\title{
Chronic sucralose consumption induces elevation of serum insulin in young healthy adults: a randomized, double blind, controlled trial
}

Nallely Bueno-Hernández ${ }^{1 \dagger}$, Marcela Esquivel-Velázquez ${ }^{1 \dagger}$, Raúl Alcántara-Suárez,2, Angélica Y. Gómez-Arauz ${ }^{1}$, Aranza J. Espinosa-Flores ${ }^{1}$, Karen L. de León-Barrera', Viridiana M. Mendoza-Martínez', Gabriela A. Sánchez Medina ${ }^{1,3}$, Mireya León-Hernández ${ }^{3}$, Alejandra Ruiz-Barranco², Galileo Escobedo ${ }^{1 *}$ and Guillermo Meléndez ${ }^{1,4^{*}}$

\begin{abstract}
Background: Non-nutritive sweeteners (NNS) are widely consumed by humans due to their apparent innocuity, especially sucralose. However, several studies link sucralose consumption to weight gain and metabolic derangements, although data are still contradictory.
\end{abstract}

Objective: To determine the effect of acute and chronic consumption of sucralose on insulin and glucose profiles in young healthy adults.

Material and methods: This was a randomized, parallel, double-blind, placebo-controlled trial conducted in healthy young adults from 18 to 35 years old, without insulin resistance. A hundred thirty seven participants were randomized into three groups: a) volunteers receiving $48 \mathrm{mg}$ sucralose, b) volunteers receiving $96 \mathrm{mg}$ sucralose, and c) controls receiving water as placebo. All participants underwent a 3-h oral glucose tolerance test (OGTT) preceded by consuming sucralose or placebo 15 min before glucose load, at two time points: week zero (Wk0) and week ten (Wk10). Serum insulin and glucose were measured every 15 min during both OGTTs.

(Continued on next page)

\footnotetext{
* Correspondence: gescobedog@msn.com;

guillermomelendezmier@outlook.es

${ }^{\dagger}$ Nallely Bueno-Hernández and Marcela Esquivel-Velázquez are co-first authors.

'Laboratory of Proteomics and Metabolomics, Research Division, General Hospital of Mexico "Dr. Eduardo Liceaga", Mexico City, Mexico

Full list of author information is available at the end of the article
}

C C The Author(s). 2020 Open Access This article is licensed under a Creative Commons Attribution 4.0 International License, which permits use, sharing, adaptation, distribution and reproduction in any medium or format, as long as you give appropriate credit to the original author(s) and the source, provide a link to the Creative Commons licence, and indicate if changes were made. The images or other third party material in this article are included in the article's Creative Commons licence, unless indicated otherwise in a credit line to the material. If material is not included in the article's Creative Commons licence and your intended use is not permitted by statutory regulation or exceeds the permitted use, you will need to obtain permission directly from the copyright holder. To view a copy of this licence, visit http://creativecommons.org/licenses/by/4.0/. The Creative Commons Public Domain Dedication waiver (http://creativecommons.org/publicdomain/zero/1.0/) applies to the data made available in this article, unless otherwise stated in a credit line to the data. 


\begin{abstract}
(Continued from previous page)
Results: Compared to WkO, consumption of sucralose for 10 weeks provoked 1 ) increased insulin concentrations at $0 \mathrm{~min}(7.5 \pm 3.4$ vs $8.8 \pm 4.1 \mu \mathrm{lU} / \mathrm{mL} ; p=0.01), 30 \mathrm{~min}(91.3 \pm 56.2$ vs $110.1 \pm 49.4 \mu \mathrm{lU} / \mathrm{mL} ; p=0.05), 105 \mathrm{~min}(47.7 \pm$ 24.4 vs $64.3 \pm 48.2 \mu \mathrm{lU} / \mathrm{mL} ; p=0.04)$ and $120 \mathrm{~min}(44.8 \pm 22.1 \mathrm{vs} 63.1 \pm 47.8 \mu \mathrm{lU} / \mathrm{mL} ; \mathrm{p}=0.01)$ in the $48 \mathrm{mg}$ sucralose group; 2$)$ increased blood glucose at $-15 \mathrm{~min}(87.9 \pm 4.6 \mathrm{vs} 91.4 \pm 5.4 \mathrm{mg} / \mathrm{dL} ; p=0.003), 0 \mathrm{~min}(88.7 \pm 4 \mathrm{vs} 91.3 \pm 6$ $\mathrm{mg} / \mathrm{dL} ; p=0.04)$ and $120 \mathrm{~min}(95.2 \pm 23.7 \mathrm{vs} 106.9 \pm 19.5 \mathrm{mg} / \mathrm{dL} ; p=0.009)$ in the $48 \mathrm{mg}$ sucralose group; 3$)$ increased area under the curve (AUC) of insulin in both 48 and $96 \mathrm{mg}$ sucralose groups (9262 vs 11,398; $p=0.02$ and 6962 vs 8394; $p=0.12$, respectively); and 4) reduced Matsuda index in the $48 \mathrm{mg}$ sucralose group ( $6.04 \pm 3.19$ vs $4.86 \pm 2.13 ; p=0.01$.

Conclusions: These data show that chronic consumption of sucralose can affect insulin and glucose responses in non-insulin resistant healthy young adults with normal body mass index (between 18.5 and $24.9 \mathrm{~kg} / \mathrm{m}^{2}$ ), however, the effects are not consistent with dose; further research is required.
\end{abstract}

Clinical trial registry: NCT03703141.

Keywords: Non-nutritive sweeteners, Sucralose, Insulin, Glucose, Placebo-controlled trial

\section{Background}

In the past 40 years, the prevalence of overweight and obesity has increased worldwide to the extent of becoming an epidemic [1]. Sugar overconsumption is widely recognized as a contributing dietary factor to obesity [2]. Consequently, the food industry has developed alternatives to reduce the amount of sugar in food and beverages by replacing it with non-nutritive sweeteners (NNS). NNS can be either artificial or natural and their ingestion provide very low or no calories at all [3]. This is the main reason why NNS are now contained in several foods and drinks that are consumed by million people around the globe $[4,5]$.

Despite NNS consumption is considered safe for humans [6-8], recent studies have shown that short or long-term use of NNS might be related to metabolic alterations, especially in glucose and insulin homoeostasis [9]; however, evidence is still inconclusive [9-11]. In this regard, NNS consumption has been associated with unbalance of the intestinal microbiota that in turn has been shown to cause metabolic disturbances [12, 13]. However, emerging evidence in obese individuals [10] and mice [11] has now suggested that NNS ingestion is directly associated with altered insulin response during oral glucose tolerance test (OGTT), especially with sucralose. In contrast, other studies have found contradictory results, where sucralose consumption had no effect on insulin or glucose responses during OGTT [14-16]. Although multiple mechanisms including gut microbiota dysbiosis and orosensory stimulation may explain these apparently contradictory results $[11,17,18]$, it is still unknown whether frequent sucralose consumption can directly disrupt the metabolic homeostasis in humans.

Thus, the aim of this study was to investigate whether acute or chronic sucralose ingestion produces insulin or glucose alterations in healthy young individuals that daily consume $48 \mathrm{mg}$ or $96 \mathrm{mg}$ sucralose for 10 weeks, a sucralose amount equivalent to one or two diet sodas, respectively.

\section{Methods \\ Trial design}

This was a randomized, parallel, double-blind, placebocontrolled trial in young healthy adults, conducted in Mexico City. It met the CONSORT criteria as recommended elsewhere [19].

The study was approved by the Ethics and Clinical Research committees of the General Hospital of Mexico Dr. Eduardo Liceaga (Approval No: DI/16/301/03/022) and followed the principles of the Declaration of Helsinki.

The study was conducted at the Laboratory of Proteomics and Metabolomics, Research Division at the General Hospital of Mexico Dr. Eduardo Liceaga. This trial was registered at clinicaltrials.gov (identifier code: NCT03703141).

\section{Selection of participants}

Healthy volunteers from both sexes, aging 18-35 years were invited to take part in the study by poster advertisements and survey invitations by e-mail and phone calls. All volunteers that agreed to take part in the clinical trial signed the informed consent and received full explanation of the purposes and procedures of the study. Eligibility of candidates to enter the study was performed according to a screening process that included medical history, physical examination, recording of anthropometric measurements and blood samples for evaluation of hematology tests, glycated hemoglobin (HbA1c), glucose, insulin, liver function tests, blood chemistry, insulin resistance by the homeostatic model assessment (HOMA) and Human Chorionic Gonadotropin Hormone (in women). HOMA was calculated as follows: (Fasting Plasma Insulin) x (Fasting Plasma Glucose/22.5). Subjects enrolled in the study met the cutoff point of 3.8, as described by $\mathrm{Qu}$ et al [20]. Eligibility criteria also 
included the acceptance of not consuming any foods or beverages containing NNS according to a list dispensed, attending the weekly appointments, and refraining from smoking and alcohol ingestion throughout the study. Women were enrolled in the study if they used at least one method of contraception in order to prevent pregnancy.

Participants with previous diagnosis of any acute or chronic disease, malabsorption syndrome or short bowel syndrome, use of corticosteroids, antibiotics or nonsteroidal anti-inflammatory drugs (NSAID) during the last 3 months prior to enter the study were excluded. Once enrolled, participants that attended less than $80 \%$ of weekly appointments, fell pregnant, smoked cigarettes or consumed alcohol were excluded from the study.

\section{Sample size}

The sample size estimation was performed using the GPower v.3.1 9.2 program [21], expecting an effect size of 0.14 , with an alpha error of 0.05 and a power of $95 \%$, for three groups and 11 repeated measures that resulted in a sample size of 44 participants per group.

\section{Randomization and blinding}

BHN randomized participants into three groups, as follows: a) subjects receiving $48 \mathrm{mg}$ sucralose, b) subjects receiving $96 \mathrm{mg}$ sucralose, and c) subjects receiving water as placebo. Each group ingested sucralose or water as placebo every day, for 10 weeks. The allocation groups were unrevealed to the participants as well as to researchers who delivered sucralose or placebo, or to who conducted the weekly follow-ups. Randomization was generated using the Web site http://www. randomization.com including 6 individuals per block.

\section{Sucralose intervention}

Sucralose solution $(20 \% \mathrm{w} / \mathrm{v}$, Tate \& Lyle Decatur, IL, USA) was diluted with pure drinking water. Clean, sterile, dark plastic bottles were filled with $60 \mathrm{~mL}$ of diluted sucralose, so that each bottle contained $48 \mathrm{mg}(2 \mathrm{mM})$ or 96 $\mathrm{mg}(4 \mathrm{mM})$ sucralose. Placebo was prepared by just filling the bottles with $60 \mathrm{~mL}$ of water. In all cases, the liquids were not visible, colorless and not flavored. Cardboard boxes were assembled, each one containing 9 bottles with the same amount of sucralose or water. RBA prepared and placed the beverages in the bottles. BHN labeled the cardboard boxes according to the randomization scheme. ASR disseminated the beverages to participants. Each volunteer received one box every week.

In order to evaluate energy intake $(\mathrm{Kcal} / \mathrm{d})$ and diet composition ( $\mathrm{g} / \mathrm{d}$ of lipids, proteins and carbohydrates), food frequency questionnaires from the past 7 days were applied in each weekly visit and intolerance symptoms or adverse events, if any, were registered. To evaluate participant dietary intake, researchers (GAAY, ASR,
EFAJ, LBKL and MMVM) were trained and administered 24-h food recalls and the Food Frequency Questionnaire with Intense Sweeteners (FFQIS), previously validated by our group [22]. To assess compliance, the empty bottles in each box were returned during weekly visits and a new box containing filled-up bottles was dispensed.

\section{Clinical evaluation of volunteers}

The participants' total cholesterol, high-density lipoproteins (HDL), low-density lipoproteins (LDL), triglycerides, waist-to-hip ratio (WHR) and NNS consumption $(\mathrm{mg} / \mathrm{d})$ were measured before starting the intervention.

At week zero (Wk0) and at week 10 (Wk10), bioimpedance and anthropometry assessments were performed using RJL Quantum IV system (RJL Systems Inc. Clinton Township, MI. 48,035, USA), a scale and a metric tape. An Oral Glucose Tolerance Test (OGTT), HbAc1, fasting glucose and fasting insulin were assessed at $\mathrm{Wk} 0$ and Wk10.

The Matsuda insulin sensitivity index was calculated for control and sucralose groups at Wk0 and Wk10, as described elsewhere [23].

Researchers (RBA and LHM) obtained blood samples. The biochemical analysis of blood samples was performed by trained personnel of the Hospital's Central Laboratory. Researchers (GAAY, ASR, EFAJ, LBKL and MMVM) collected anthropometrical and bioimpedance measurements from the participants and calculated WHR and Matsuda index.

\section{Oral Glucose Tolerance Tests}

OGTTs were performed in participants with $8-10 \mathrm{~h}$ fasting. Briefly, a cannula was introduced in the antecubital vein. Fifteen minutes before the glucose load ( $75 \mathrm{~g}$ in 240 $\mathrm{mL}$ of water), one dose (one bottle) of sucralose or placebo was drank by each participant. Blood samples were drawn at -15 min (immediately before drinking sucralose or placebo), at $0 \mathrm{~min}$ (immediately before drinking the glucose load), and at 15, 30, 45, 60, 75, 90, 105, 120 and $180 \mathrm{~min}$, consecutively. Blood samples were sent to the hospital's central lab for immediate glucose and insulin measurements. At the end of the OGTT, all participants received a light lunch. Plasma glucose was measured using a glucose analyzer (Beckman Coulter, glucose, CA, USA) and plasma insulin was measured through an enzymelinked immunosorbent assay (ELISA, Beckman Coulter, Ultrasensitive insulin, CA, USA).

\section{Statistical analysis}

Data entry was performed twice by two separate managers. Demographic data were reported as means and standard deviations or proportions. The KolmogorovSmirnov test was used to assess normality for each variable. 
Areas under the curve (AUC), maximal concentration and time to maximal concentration from Wk0 and Wk10 of the OGTT, were also calculated for each group by the trapezoid method, using the pk module of the Stata 15 software (StataCorp LLC, College Station, TX, USA).

Differences between $\mathrm{Wk} 0$ and $\mathrm{Wk10}$ of each group were evaluated by two-tailed paired-t tests. Differences between all groups at the same time point (Wk0 or Wk10) were compared by One-Way ANOVA. Differences between two groups at the same time points were analyzed using two-tailed t-tests.

Univariant Analysis of Variance was performed to determine the existence of interactions between interventions (sucralose and placebo) and time (Wk0 and Wk10). A two-way ANOVA was performed to analyze differences between Wk0 and Wk10, using the Bonferroni test to adjust for multiple comparisons.

The IBM-SPSS version 23 statistical package (Chicago, Ill, USA) was used for the analysis. A $p$ value $<0.05$ was set as statistically significant and p between 0.05 and 0.1 was considered to show a tendency.

\section{Results}

Two hundred forty nine young adults were invited to the study (from February 2016 to June 2019); 137 accepted to participate and met the inclusion and exclusion criteria to enter the study. After randomization, assignments were 45 subjects in the control group (placebo), 46 subjects in the $48 \mathrm{mg}$ sucralose group, and 46 subjects in the $96 \mathrm{mg}$ sucralose group. By the end of Wk10, only 95 participants completed the study; 34 in the control group, 30 in the $48 \mathrm{mg}$ sucralose group and 31 in the $96 \mathrm{mg}$ sucralose group, and these were considered for statistical analyses. The principal reasons for withdrawal were intolerance to the sweetness of sucralose and digestive functional disorders (Fig. 1).

Baseline characteristics in all three groups were similar, including age, HOMA-IR, HbAc1, BMI, WHR, body composition (body fat, fat free mass, lean dry mass and total body water), total cholesterol, HDL, LDL and triglycerides. Women were more prevalent than men in the three study groups (Table 1).

\section{Chronic consumption of sucralose increases insulin responses in OGTT}

In order to identify if the consumption of sucralose for 10 weeks (chronic effect) might provoke derangements in the carbohydrate metabolism, we compared glucose and insulin levels in OGTTs at Wk0 and at Wk10. In the control group, no differences were found in insulin and glucose concentrations between Wk0 and Wk10 (Fig. $2 \mathrm{~d}$ and Fig. 3d). In the $48 \mathrm{mg}$ sucralose group, significant increases in insulin were found at $0 \mathrm{~min}(7.5 \pm$ $3.4 \mu \mathrm{IU} / \mathrm{mL}$ vs $8.8 \pm 4.1 \mu \mathrm{IU} / \mathrm{mL} ; p=0.01)$, at $30 \mathrm{~min}$ $(91.3 \pm 56.2 \mu \mathrm{IU} / \mathrm{mL}$ vs. $110.1 \pm 49.4 \mu \mathrm{IU} / \mathrm{mL} ; p=0.05)$,

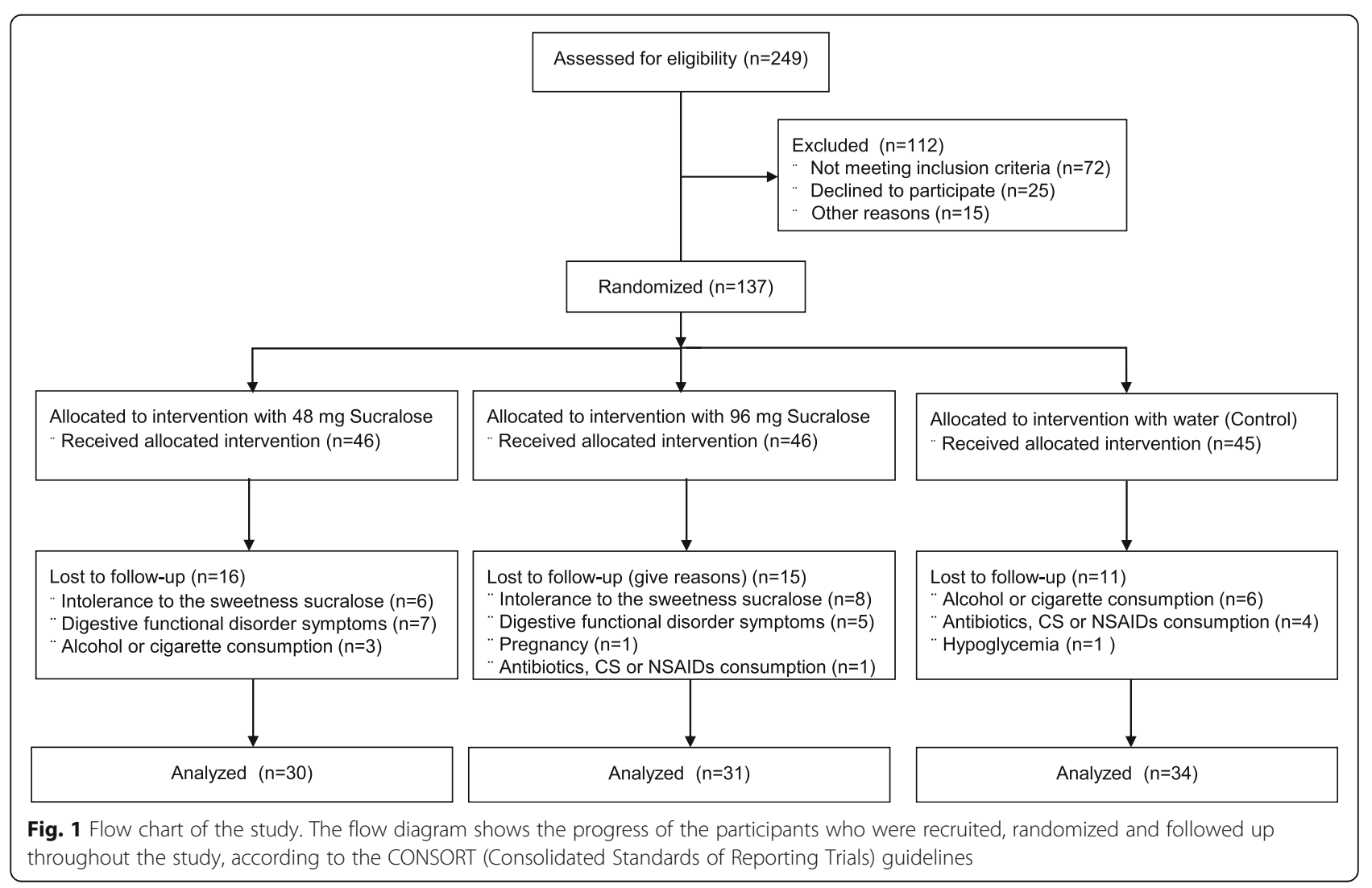


Table 1 Baseline characteristics of the volunteers

\begin{tabular}{|c|c|c|c|c|}
\hline & $\begin{array}{l}48 \mathrm{mg} \\
\boldsymbol{n}=30\end{array}$ & $\begin{array}{l}96 \mathrm{mg} \\
\boldsymbol{n}=31\end{array}$ & $\begin{array}{l}\text { Control } \\
\boldsymbol{n}=34\end{array}$ & $p^{a}$ \\
\hline Age, years $( \pm S D)$ & $22.9 \pm 3.5$ & $22.6 \pm 2.8$ & $22 \pm 3.2$ & 0.86 \\
\hline \multicolumn{5}{|l|}{ Gender, $\mathrm{n}$} \\
\hline Females & 20 & 18 & 20 & 0.75 \\
\hline Males & 10 & 13 & 14 & 0.43 \\
\hline $\mathrm{BMI}, \mathrm{kg} / \mathrm{m}^{2}$ & $24.1 \pm 2.9$ & $23.8 \pm 3.3$ & $24.2 \pm 3.8$ & 0.84 \\
\hline WHR, $\mathrm{cm} / \mathrm{cm}$ & $0.8 \pm 0.07$ & $0.8 \pm 0.08$ & $0.81 \pm 0.07$ & 0.69 \\
\hline Body fat, $\%$ & $37.2 \pm 5.2$ & $34.4 \pm 5.9$ & $35.5 \pm 7.2$ & 0.21 \\
\hline Fat free mass, kg & $39.9 \pm 8.2$ & $43.1 \pm 9.2$ & $41.6 \pm 8.5$ & 0.34 \\
\hline Lean dry mass, kg & $11.3 \pm 2.03$ & $12.04 \pm 2.1$ & $11.6 \pm 2.02$ & 0.42 \\
\hline Total body water, $\%$ & $44.8 \pm 4.3$ & $47.09 \pm 4.5$ & $46.2 \pm 5.4$ & 0.19 \\
\hline Total cholesterol, mg/dL & $163.4 \pm 28.3$ & $165.9 \pm 33.5$ & $161.5 \pm 27.9$ & 0.83 \\
\hline HDL cholesterol, mg/dL & $41.6 \pm 9.6$ & $45.2 \pm 10.3$ & $43.09 \pm 9.5$ & 0.34 \\
\hline LDL cholesterol, mg/dL & $95.5 \pm 22.5$ & $98.2 \pm 29.7$ & $97.2 \pm 24.8$ & 0.91 \\
\hline Triglycerides, mg/dL & $125.5 \pm 110.5$ & $102.5 \pm 69.7$ & $99.8 \pm 58.3$ & 0.39 \\
\hline HOMA-IR & $1.71 \pm 0.7$ & $1.48 \pm 0.7$ & $1.61 \pm 0.6$ & 0.41 \\
\hline $\mathrm{HbAcl}, \mathrm{mg} / \mathrm{dL}( \pm \mathrm{SD})$ & $5.2 \pm 0.2$ & $5.1 \pm 0.3$ & $5.2 \pm 0.2$ & 0.38 \\
\hline \multicolumn{5}{|l|}{ Intake } \\
\hline Energy, Kcal/d & $1935.9 \pm 681.7$ & $2133 . \pm 965.8$ & $2264.1 \pm 1247$ & 0.42 \\
\hline Lipids, g/d & $67.6 \pm 43.4$ & $69.2 \pm 43.3$ & $71.5 \pm 59.9$ & 0.95 \\
\hline Protein, $\mathrm{g} / \mathrm{d}$ & $94.4 \pm 60.6$ & $100.7 \pm 44.3$ & $103.9 \pm 74.8$ & 0.82 \\
\hline Carbohydrate, g/d & $227.8 \pm 59.32$ & $264.7 \pm 133.9$ & $289.4 \pm 118.4$ & 0.08 \\
\hline $\mathrm{NNS}, \mathrm{mg} / \mathrm{d}$ & $102 \pm 287.5$ & $68 \pm 140.3$ & $74.34 \pm 141.5$ & 0.84 \\
\hline Consumption of NNS n (\%) & $21(70)$ & $20(64)$ & $23(73)$ & 0.56 \\
\hline Adherence to intervention (\%) & $94.14 \pm 11.81$ & $86.07 \pm 19.12$ & $87 \pm 20.37$ & 0.16 \\
\hline
\end{tabular}

$B M I$ body mass index, HOMA hemoglobin model assessment, $H b 1 A c$ hemoglobin glycated, $H D L$ high density lipoproteins, $L D L$ low density lipoproteins, $S D$ standard deviation, WHR waist-to-hip ratio, $g / d$ grams per day ${ }^{a}$ One-Way ANOVA

at $105 \mathrm{~min}(47.7 \pm 24.4 \mu \mathrm{IU} / \mathrm{mL}$ vs. $64.3 \pm 48.2 \mu \mathrm{IU} / \mathrm{mL}$; $p=0.04)$, and at $120 \mathrm{~min}(44.8 \pm 22.1 \mu \mathrm{IU} / \mathrm{mL}$ vs. $63.1 \pm$ $47.8 \mu \mathrm{IU} / \mathrm{mL} ; \mathrm{p}=0.01$ ) (Fig. $2 \mathrm{~b}$ ). In the same group, a significant increase in glucose was found at $-15 \mathrm{~min}$ $(87.9 \pm 4.6 \mathrm{mg} / \mathrm{dL}$ vs $91.4 \pm 5.4 \mathrm{mg} / \mathrm{dL} ; p=0.003)$, at 0 $\min (88.7 \pm 4 \mathrm{mg} / \mathrm{dL}$ vs. $91.3 \pm 6 \mathrm{mg} / \mathrm{dL} ; \mathrm{p}=0.04)$, and at $120 \mathrm{~min}(95.2 \pm 23.7 \mathrm{mg} / \mathrm{dL}$ vs $106.9 \pm 19.5 \mathrm{mg} / \mathrm{dL} ; \mathrm{p}=$ 0.01). Although glucose concentration at Wk10 was higher than that found at $\mathrm{Wk} 0$, differences were not significant (Fig. 3b). In the $96 \mathrm{mg}$ sucralose group, insulin and glucose concentrations increased but none reached significant differences (Fig. 2c and Fig. 3c).

To compare the global response to insulin during OGTTs, we performed insulin and glucose AUC analyses. First, we analyzed if there were interactions between type of intervention and consumption time. No interaction between type of intervention (control, $48 \mathrm{mg}$ or $96 \mathrm{mg}$ sucralose) and consumption time (Wk0 and Wk10) was found in glucose AUC $(\mathrm{F}(2,184)=0.00, p=$ 1.00). Consumption time had no effect on glucose AUC
$(\mathrm{F}(1,184)=0.00, \mathrm{p}=1.00)$; in contrast, type of intervention showed a significant effect $(\mathrm{F}(2,184)=3.327, p=$ $\left.0.038, \eta^{2}=0.035,1-\beta=0.624\right)$. A similar trend was found in the AUC of insulin, where no interaction between type of intervention and consumption time was observed $(\mathrm{F}(2,184)=0.45, p=0.63)$. Consumption time did not have a significant effect on the insulin AUC, however, it showed a tendency to increase $(\mathrm{F}(1,184)=2.77, p=0.10)$. In contrast, type of intervention had a significant effect on the AUC of insulin $\left(F(2,184)=3.74, p=0.03, \eta^{2}=\right.$ $0.039,1-\beta=0.679)$. Two-way ANOVA analysis showed no interaction between type of intervention and consumption time in both glucose and insulin AUCs ( $\mathrm{F}(4$, $366)=0.255, p=0.91)$. However, type of intervention showed a significant effect on (a) the insulin AUC when compared subjects of the Bonferroni's correction showed that this effect was significant for insulin AUC between $48 \mathrm{mg}$ sucralose group versus participants of the $96 \mathrm{mg}$ sucralose group (means difference: - 2652.203, SE: 975.45, CI 95\%: - 5008.957, $-295.449 ; p=0.02$ ), and (b) 


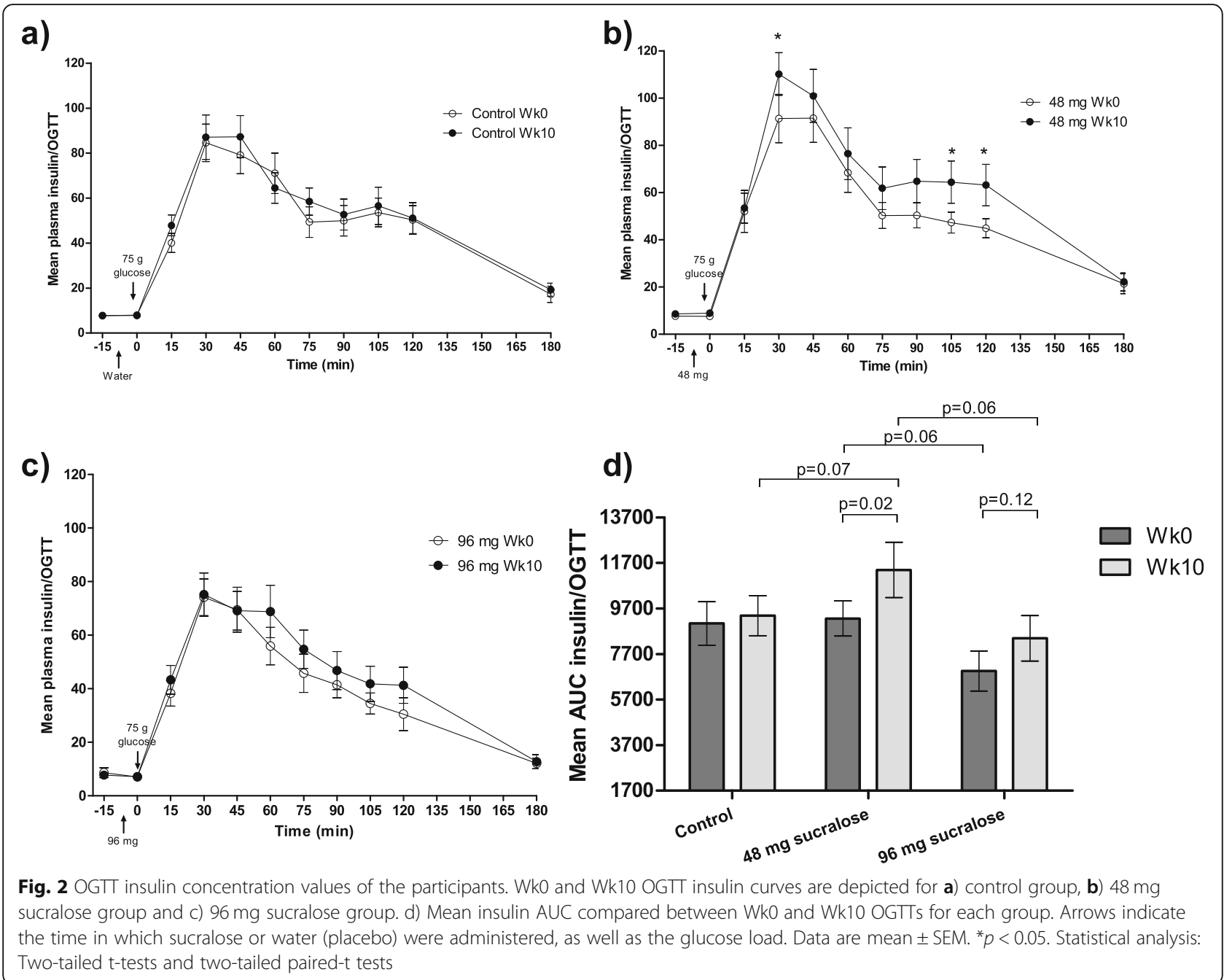

glucose AUC when compared volunteers of the $48 \mathrm{mg}$ sucralose group versus control subjects (means difference: -1537.81, SE: 603.475, CI 95\%: - 2995.848, 79.772; $p=0.035$ ) (Table 2).

We then compared both glucose and insulin AUCs at Wk0 and at Wk10. Insulin AUC showed the most significant increases after 10 weeks of exposure to $48 \mathrm{mg}$ sucralose (AUC Wk0 $=9262 \pm 4225$ vs AUC Wk10 $=11,398 \pm$ 6641; $\mathrm{p}=0.02$ ) but not to $96 \mathrm{mg}$ sucralose (AUC $\mathrm{Wk} 0=$ $6962 \pm 4899$ vs AUC $\mathrm{Wk} 10=8394 \pm 5567 ; p=0.12)$ (Fig. 2d). Insulin AUC showed no significant differences between Wk0 and Wk10. However, insulin AUC tended to increase in the $48 \mathrm{mg}$ sucralose group with respect to that found in the control group at Wk10 (AUC Wk10 48 $\mathrm{mg}=11,398 \pm 6641$ vs AUC Wk10 control $=9397 \pm 5126$; $p=0.07)$. At $\mathrm{W} \mathrm{k} 0$, insulin AUC tended to decrease in the $96 \mathrm{mg}$ sucralose group as compared to that found in the $48 \mathrm{mg}$ sucralose group (AUC Wk0 $96 \mathrm{mg}=6962 \pm 4899 \mathrm{vs}$ AUC Wk0 $48 \mathrm{mg}=9262 \pm 4225 ; p=0.06)$. At Wk10, insulin AUC tended to decrease in the $96 \mathrm{mg}$ sucralose group as compared to that found in the $48 \mathrm{mg}$ sucralose group (AUC Wk10 $96 \mathrm{mg}=8394 \pm 5567$ vs AUC Wk10 $48 \mathrm{mg}=$ $11,398 \pm 6641 \mathrm{p}=0.06$ ) (Fig. 2d).

Similarly, glucose AUC showed no significant changes after 10 weeks of drinking $48 \mathrm{mg}$ sucralose; however, a tendency to increase was seen (AUC Wk0 $=18,267 \pm$ 2858 vs AUC Wk10 = 19,408 $\pm 2904 ; \mathrm{p}=0.06$ ) (Fig. 3d).

We then analyzed glucose AUCs between subjects receiving any sucralose amount (either 48 or $96 \mathrm{mg}$ sucralose) and those drinking placebo. After 10 weeks of exposure, we found that volunteers receiving any sucralose concentration had higher glucose and insulin levels than those found in controls receiving placebo (for glucose, $\mathrm{Wk} 0=18,141 \pm 3877$ vs $\mathrm{Wk} 10=18,885 \pm 3332, p=$ 0.01 ; for insulin, Wk $0=8093 \pm 4687$ vs Wk10 $=9871 \pm$ 6253, $p=0.006$ ). It is worth mentioning that both glucose and insulin AUCs were similar when compared Wk0 versus Wk10 in the control group (Fig. 4).

Furthermore, the maximum insulin peak significantly increased in the $48 \mathrm{mg}$ sucralose group after 10 weeks of 


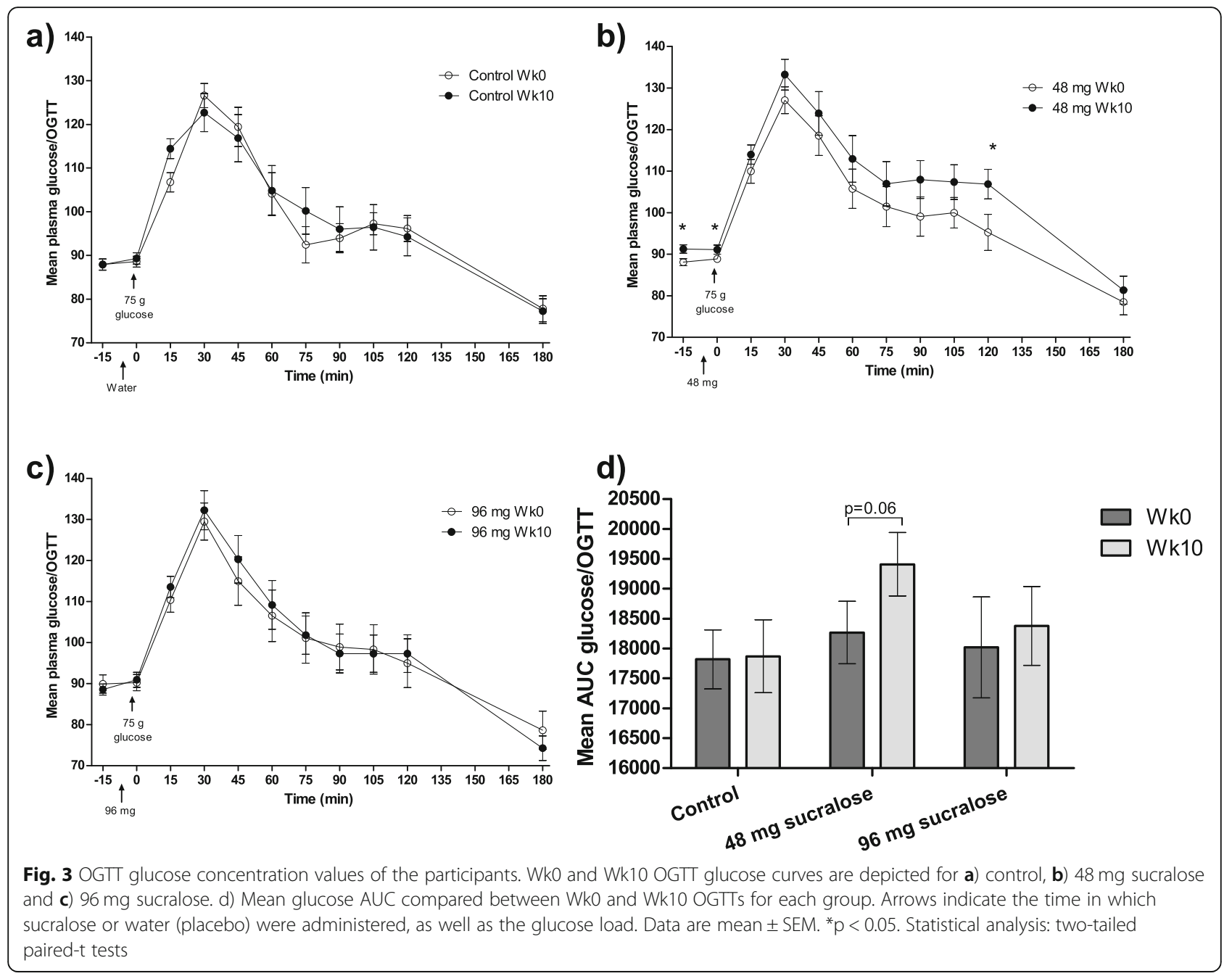

Table 2 Differences between experimental groups (48 mg and $96 \mathrm{mg}$ sucralose) and control group at Wk0 and Wk10 OGTT

\begin{tabular}{|c|c|c|c|c|c|c|c|}
\hline & \multirow{2}{*}{$\begin{array}{l}\text { (I) } \\
\text { Group }\end{array}$} & \multirow{2}{*}{$\begin{array}{l}\text { (J) } \\
\text { Group }\end{array}$} & \multirow{2}{*}{$\begin{array}{l}\text { Media difference } \\
(I-J)\end{array}$} & \multirow{2}{*}{$\begin{array}{l}\text { Standard } \\
\text { error }\end{array}$} & \multirow[t]{2}{*}{$p$} & \multicolumn{2}{|c|}{ 95\% Confidence interval } \\
\hline & & & & & & Lower Bound & Upper Bound \\
\hline \multirow[t]{6}{*}{ Glucose, AUC } & \multirow[t]{2}{*}{ Control } & $48 \mathrm{mg}$ & -1537.81 & 603.48 & $0.03^{\mathrm{a}}$ & -2995.85 & -79.77 \\
\hline & & 96 mg & -509.85 & 598.28 & 1.00 & -1955.34 & 935.64 \\
\hline & \multirow[t]{2}{*}{$48 \mathrm{mg}$} & Control & 1537.81 & 603.48 & $0.03^{\mathrm{a}}$ & 79.77 & 2995.85 \\
\hline & & $96 \mathrm{mg}$ & 1027.96 & 617.01 & 0.29 & -462.79 & 2518.70 \\
\hline & \multirow[t]{2}{*}{96 mg } & Control & 509.85 & 598.28 & 1.00 & -935.64 & 1955.34 \\
\hline & & $48 \mathrm{mg}$ & -1027.96 & 617.01 & 0.29 & -2518.70 & 462.79 \\
\hline \multirow[t]{6}{*}{ Insulin, AUC } & \multirow[t]{2}{*}{ Control } & $48 \mathrm{mg}$ & -1104.65 & 954.05 & 0.75 & -3409.70 & 1200.40 \\
\hline & & $96 \mathrm{mg}$ & 1547.55 & 945.84 & 0.31 & -737.66 & 3832.77 \\
\hline & \multirow[t]{2}{*}{$48 \mathrm{mg}$} & Control & 1104.65 & 954.05 & 0.75 & -1200.40 & 3409.70 \\
\hline & & $96 \mathrm{mg}$ & $2652.20^{\mathrm{a}}$ & 975.45 & 0.02 & 295.45 & 5008.96 \\
\hline & \multirow[t]{2}{*}{96 mg } & Control & -1547.55 & 945.84 & 0.31 & -3832.77 & 737.66 \\
\hline & & $48 \mathrm{mg}$ & $-2652.20^{\mathrm{a}}$ & 975.45 & 0.02 & -5008.96 & -295.45 \\
\hline
\end{tabular}

\footnotetext{
${ }^{a}$ The mean difference is significant at 0.05 level. Two-way ANOVA adjustment for multiple comparisons with Bonferroni
} 

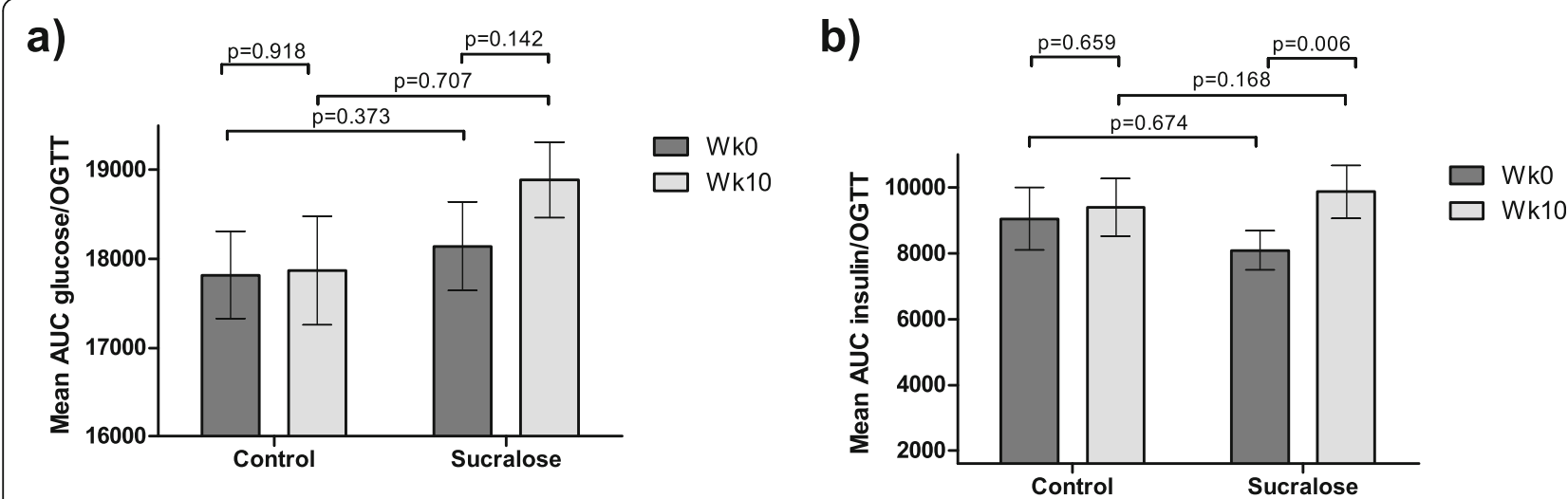

Fig. 4 Analysis of WkO and Wk10 glucose and insulin AUC between the sucralose exposed group (48 mg \& 96 mg groups) and not exposed group (control). Data are mean \pm SEM. ${ }^{*} p<0.05$. Statistical analysis: Two-tailed paired-t tests

intervention (Max [Ins] Wk0 $=106.1 \pm 57.9$ vs Max [Ins] Wk10 = 130.9 $\pm 60.51, \mathrm{p}=0.01)$ (Table 3).

\section{Sucralose chronic consumption modifies insulin sensitivity}

The Matsuda index for insulin sensitivity was calculated at $\mathrm{Wk} 0$ and $\mathrm{Wk} 10$ for each group. After 10 weeks, the Matsuda index showed a significant reduction in the 48 mg sucralose group $(\mathrm{Wk} 0=6.04 \pm 3.19$ vs $\mathrm{Wk} 10=$ $4.86 \pm 2.13 ; \mathrm{p}=0.01)$, but not in the $96 \mathrm{mg}$ sucralose group $(\mathrm{Wk} 0=7.93 \pm 4.6, \quad \mathrm{Wk} 10=7.09 \pm 4.71, \quad p=0.30)$ (Table 3).

Overall, food consumption showed no significant differences among the three intervention groups in carbohydrates, lipids, proteins, and energy intake (Table 3). After 10 weeks, the average carbohydrate intake decreased only in control subjects (Wk0 $=289.4 \pm 118.4$ vs $\mathrm{Wk} 10=250.7 \pm 123.5 ; p=0.12)$, whereas in volunteers receiving sucralose increased $(\mathrm{Wk} 048 \mathrm{mg}=227.9 \pm 59.3$ vs Wk10 $48 \mathrm{mg}=252.9 \pm 86.7 ; p=0.18$; Wk0 $96 \mathrm{mg}=$ $264.7 \pm 133.9$ vs Wk10 $96 \mathrm{mg}=286.5 \pm 132.7 ; p=0.42$ ). However, no significant differences were reached.

Adherence to intervention was also similar in the three groups; however, the highest adherence rate was found in the $48 \mathrm{mg}$ sucralose group (94\%) while subjects in the $96 \mathrm{mg}$ sucralose group showed the lowest adherence rate (86\%).

\section{Acute consumption of sucralose has little to no impact in} the insulin response during OGTT

The effect of the acute consumption of sucralose was assessed by comparing insulin values at $-15 \mathrm{~min}$ and at 0 min of the OGTTs performed at Wk0. No differences were found between placebo and sucralose groups (48 mg or $96 \mathrm{mg}$ ), (Figs. 2 and 3).

\section{Adverse events}

Two volunteers developed symptoms of hypoglycemia during OGTTs, one of the control group and the other one of the $96 \mathrm{mg}$ sucralose group. However, these symptoms were mild and volunteers recovered soon. Volunteers also reported several digestive functional disorders (Fig. 1).

\section{Discussion}

The most notable findings observed in the study were changes in insulin concentrations, insulin AUCs, and glucose AUCs in the $48 \mathrm{mg}$ sucralose intervention group at 10th week. The most significant changes in insulin were found at $0,30,105$ and $120 \mathrm{~min}$, possibly as a delayed metabolic response generated to compensate the insulin increment to keep glucose on target. Likewise, the effect on the AUC was greater in insulin than in glucose. This data suggest that chronic consumption of sucralose reduces insulin sensitivity in young adults; in consequence, insulin production tended to increase with the aim of keeping glucose levels in normal values. Insulin did not only change, also a reduction in the Matsuda Index was found in the same group, which in turn supports the idea that insulin exerted a compensatory response to chronic sucralose consumption.

Unexpectedly, these effects were only significant in the $48 \mathrm{mg}$ sucralose group but not in the $96 \mathrm{mg}$ sucralose group; possible explanations are discussed later.

One unexpected finding was the high variability in OGTT glucose and insulin time points among participants; we consider that this resulted from the high HOMA value that we decided to set as cut off point $(<3.8)$.

Several studies have shown that sucralose is not physiologically innocuous. Pepino et al, reported that acute consumption of $48 \mathrm{mg}$ sucralose increased glucose concentrations as well as insulin AUC in a 5 h OGTT in individuals with obesity [10]. However, this work was criticized due to the small number of volunteers enrolled, mostly women [24]. We did not find any differences attributable to the acute consumption of sucralose, however, we found differences attributable to 
Table 3 Change on metabolic parameters and macronutrients consumption in the diet

\begin{tabular}{llll}
\hline & WkO & Wk10 & $\mathrm{p}^{\mathrm{a}}$ \\
\hline Insulin, AUC & & & \\
$48 \mathrm{mg}$ sucralose & $9262 \pm 4225$ & $11,398 \pm 6641$ & 0.02 \\
$96 \mathrm{mg}$ sucralose & $6962 \pm 4899$ & $8394 \pm 5567$ & 0.12 \\
Control & $9054 \pm 5571$ & $9397 \pm 5126$ & 0.65 \\
p $^{\text {b }}$ & 0.135 & 0.125 &
\end{tabular}

Glucose, AUC

$48 \mathrm{mg}$ sucralose
$96 \mathrm{mg}$ sucralose
Control
$p^{\mathrm{b}}$

Matsuda

$\begin{array}{ll}48 \mathrm{mg} \text { sucralose } & 6.04 \pm 3.19 \\ 96 \mathrm{mg} \text { sucralose } & 7.93 \pm 4.63 \\ \text { Control } & 6.8 \pm 3.35 \\ \text { p }^{\mathrm{b}} & 0.14\end{array}$

$\operatorname{Max}[\mathrm{Glu}]$

$\begin{array}{ll}48 \mathrm{mg} \text { sucralose } & 133.06 \pm 20.79 \\ 96 \mathrm{mg} \text { sucralose } & 133.45 \pm 29.72 \\ \text { Control } & 131.94 \pm 21.19 \\ \mathrm{p}^{\mathrm{b}} & 0.96\end{array}$

$\operatorname{Max}[\operatorname{lns}]$

$48 \mathrm{mg}$ sucralose

$96 \mathrm{mg}$ sucralose

Control

$p^{b}$

Time to max [Glu]

$48 \mathrm{mg}$ sucralose

$96 \mathrm{mg}$ sucralose

Control

$p^{b}$

$$
\begin{aligned}
& 18,267 \pm 2858 \\
& 18,019 \pm 4705 \\
& 17,820 \pm 2872 \\
& 0.883
\end{aligned}
$$

$19,408 \pm 2904$

$18,380 \pm 3677$

$17,870 \pm 3557$

0.195

$4.86 \pm 2.13$

$7.09 \pm 4.72$

$6.14 \pm 3.41$

0.05

$141.17 \pm 18.59$

$137.61 \pm 25.33$

$135.12 \pm 23.53$

0.56

$106.10 \pm 58$

Time to Max [Ins]

$48 \mathrm{mg}$ sucralose

$96 \mathrm{mg}$ sucralose

Control

$p^{b}$

BMl, $\mathrm{kg} / \mathrm{m}^{2}$

$48 \mathrm{mg}$ sucralose
$96 \mathrm{mg}$ sucralose
Control
$\mathrm{p}^{\mathrm{b}}$

Carbohydrates, g/d

$48 \mathrm{mg}$ sucralose

$96 \mathrm{mg}$ sucralose
$85.42 \pm 42.67$

$100 \pm 56.07$

0.29

$$
\begin{aligned}
& 34 \pm 18.45 \\
& 36.77 \pm 20.06 \\
& 36.18 \pm 9.85 \\
& 0.78
\end{aligned}
$$

$40.5 \pm 14.82$

$40.65 \pm 17.4$

$45 \pm 19.19$

0.49

$$
\begin{aligned}
& 24.2 \pm 2.9 \\
& 23.7 \pm 3.3 \\
& 24.2 \pm 3.8
\end{aligned}
$$$$
0.84
$$

$130.9 \pm 60.51$

$90.42 \pm 50.41$

$108.94 \pm 62.15$

0.02

$\begin{array}{ll}40.5 \pm 23.35 & 0.11 \\ 34.84 \pm 19.51 & 0.58 \\ 36.18 \pm 20.27 & 1.00 \\ 0.55 & \end{array}$

$38.5 \pm 20.35 \quad 0.58$

$45.48 \pm 17.53 \quad 0.23$

$48.09 \pm 23.87$

0.17

$$
\begin{aligned}
& 24.2 \pm 3.1 \\
& 23.6 \pm 3.2 \\
& 24.1 \pm 3.9 \\
& 0.76
\end{aligned}
$$

$$
227.9 \pm 59.3
$$

$264.7 \pm 133.9$
Table 3 Change on metabolic parameters and macronutrients consumption in the diet (Continued)

\begin{tabular}{llll}
\hline & Wk0 & Wk10 & $p^{\text {a }}$ \\
\hline Control & $289.4 \pm 118.4$ & $250.7 \pm 123.5$ & 0.12 \\
$p^{\text {b }}$ & 0.08 & 0.42 & \\
Lipids, g/d & & & \\
$48 \mathrm{mg}$ sucralose & $67.6 \pm 43.4$ & $81.6 \pm 40.4$ & 0.10 \\
$96 \mathrm{mg}$ sucralose & $69.2 \pm 43.4$ & $74.2 \pm 40.9$ & 0.63 \\
Control & $71.6 \pm 59.9$ & $62.1 \pm 26.6$ & 0.29 \\
$p^{\text {b }}$ & 0.95 & 0.11 &
\end{tabular}

Proteins, g/d

$\begin{array}{llll}48 \mathrm{mg} \text { sucralose } & 94.4 \pm 60.6 & 97.47 \pm 44.4 & 0.86 \\ 96 \mathrm{mg} \text { sucralose } & 100.8 \pm 44.4 & 94.9 \pm 82.9 & 0.32 \\ \text { Control } & 103.9 \pm 74.8 & 84.7 \pm 32.9 & 0.09 \\ \text { p }^{\text {b }} & 0.824 & 0.427 & \end{array}$

Energy, Kcal/d

$\begin{array}{llll}48 \mathrm{mg} \text { sucralose } & 1935.9 \pm 681.8 & 2170.7 \pm 732.3 & 0.10 \\ 96 \mathrm{mg} \text { sucralose } & 2133.1 \pm 965.8 & 2235.7 \pm 917.5 & 0.65 \\ \text { Control } & 2264.8 \pm 1247.2 & 1941.6 \pm 710.7 & 0.09 \\ \text { p }^{\mathrm{b}} & 0.42 & 0.30 & \end{array}$

0.09

0.46

$\mathrm{HbA1c}$

$\begin{array}{llll}48 \mathrm{mg} \text { sucralose } & 5.23 \pm 0.21 & 5.26 \pm 0.26 & 0.51 \\ 96 \mathrm{mg} \text { sucralose } & 5.15 \pm 0.3 & 5.25 \pm 0.26 & 0.03 \\ \text { Control } & 5.22 \pm 0.23 & 5.24 \pm 0.24 & 0.55 \\ \mathrm{p}^{\mathrm{b}} & 0.38 & 0.94 & \end{array}$

AUC area under the curve, $B M I$ body mass index, Hb1AC hemoglobin glycated, HOMA homeostatic model assessment, WkO week 0, Wk10 week $10,48 \mathrm{mg}$ $(\mathrm{n}=30)$; $96 \mathrm{mg}(\mathrm{n}=31)$; Control $(\mathrm{n}=34)$. Media \pm standard deviation ${ }^{a}$ Two-tailed paired-t tests; ${ }^{\mathrm{b}}$ Differences between groups, One-Way ANOVA

its chronic consumption: maximum insulin concentration (or peak insulin) was increased in the $48 \mathrm{mg}$ sucralose group and two OGTT insulin time points showed reduction in the $96 \mathrm{mg}$ sucralose group as compared to placebo (105 min and $120 \mathrm{~min}$ ). Nonetheless, Pepino's data in obese patients resemble those here reported in young healthy volunteers with normal BMI, which suggests that there is induced reduction in insulin sensitivity associated with sucralose consumption for 10 weeks. Also, Sylvetsky et al observed an increase in insulin levels (peak insulin and AUC) but not glucose, during a two-hour OGTT in healthy adults who received one diet soda containing sucralose and acesulfame $\mathrm{K}$ prior to the glucose load. This effect was also observed when volunteers received sucralose and acesulfame $K$ in seltzer water, but it was not statistically significant [25].

Furthermore, Lertrit et al reported in a randomized double-blind cross over study that daily oral ingestion of $200 \mathrm{mg}$ encapsulated sucralose for 4 weeks decreased whole body and hepatic insulin sensitivities (Matsuda index and HOMA-IR, respectively) in 15 healthy 
volunteers without obesity (11 female). Sucralose was administered in capsules, which avoided the oral response to the sweetness [26]. Nonetheless, the effect that both Lertrit et al and we found in insulin sensitivity suggests that sucralose may reduce insulin sensitivity through extraoral responses.

On the contrary, the 12-week study in 46 normoglycemic male volunteers who received $\sim 333.3 \mathrm{mg}$ encapsulated sucralose or placebo $3 \mathrm{x} /$ day test, showed no significant differences between $\mathrm{Wk} 0$ and Wk10 OGTTs in HBA1c, glucose, insulin, and C peptide [27]. In light of this information, our results support the hypothesis that continuous consumption of sucralose affects insulin release to take glucose into the organs. The individuals in our study, healthy young adults with no previous carbohydrate metabolism impairment, were challenged with a dose equivalent to one $(48 \mathrm{mg}$ ) or two cans $(96$ $\mathrm{mg}$ ) of regular diet beverages, an amount that is easily reachable in modern diet.

We also found a statistically significant increase in HbA1c after consumption for 10 weeks of $96 \mathrm{mg}$ sucralose. Davis et al also reported an increase in HbAlc in Hispanic young individuals with overweight or obesity who were frequent consumers of beverages with NNS at least for 1 year [28]. This effect could also depend on the diet content, for instance, sucralose consumption $(\geq 5$ days) in combination with an imbalanced diet has been shown to trigger a neuronal response which stimulates food intake in a fruit fly model [29]; nevertheless, in the present study no significant differences were found in the intake of macronutrients in any of the groups before and after the intervention for 10 weeks. In view of these results, it seems that sucralose has metabolic effects that interfere with glucose and insulin homeostasis, possibly due to different mechanisms such as gut microbiota dysbiosis or sweet taste receptors expressed in the digestive system [30-32], which play an important role in both glucose absorption and insulin secretion.

It is pertinent to mention that the effects of sucralose consumption for 10 weeks on insulin and glucose were only observed in the $48 \mathrm{mg}$ sucralose group and not in the $96 \mathrm{mg}$ sucralose group. Several explanations are possible that can be partially involved in this phenomenon. For instance, lower adherence to intervention in the 96 $\mathrm{mg}$ sucralose group than in the $48 \mathrm{mg}$ group; however, this difference was not so great to completely explain what was observed. Likewise, the excessive sweetness of this dose of sucralose may have provoked an under consumption of the NSS that was not reported by participants. Other possible explanations may involve different mechanisms related to glucose and insulin homeostasis, like gut microbiota dysbiosis, sweet taste receptors response, cephalic response to sucralose, among others, that are discussed below.
Sucralose induces a cephalic phase in the insulin response without any other stimulus, which can influence digestion and metabolism leading to the release of several hormones such as GLP-1, ghrelin, and insulin after oral exposure [17]. In our sample, we could not determine the cephalic phase of the insulin response, a research question that will be answered further.

Likewise, gut microbiota could also play a role in explaining the differences between groups. In this sense, Suez et al reported impaired glucose tolerance in mice after exposure to saccharin, sucralose or aspartame in the drinking water for 10 weeks, an effect that was dependent on the alteration in gut microbiota caused by NNS [11]. Moreover, they reported a significant correlation between NNS consumption and metabolic syndrome in 381 individuals without diabetes (56\% females); and significantly poorer glycemic responses 5 7 days after saccharin consumption for 1 week in four out of seven healthy volunteers who were exposed to NNS for 7 days; in both cases, alterations in the microbiota composition (dysbiosis) were present in those individuals exposed to NNS [11]. This data highlight the importance of gut microbiota in glucose and insulin homeostasis; also, they show the great variability in microbiota among individuals, and how it affects glycemic responses, as not all individuals exposed to NNS featured the same outcomes. In our study we did not assessed changes in gut microbiota related to sucralose consumption; it is possible that more individuals with dysbiosis are present in either the $96 \mathrm{mg}$ sucralose group than in the $48 \mathrm{mg}$ sucralose group, which can bias the glucose and insulin responses during OGTT, especially considering that the amount of NNS consumed between these two groups tended to differ.

Other mechanisms that may also explain the response observed in the $96 \mathrm{mg}$ sucralose group can be related to sweet receptor signaling in cells. This receptor, a TAS1R2/TAS1R3 heterodimer, is expressed in several tissues, from the upper gastrointestinal tract to intestinal brush and enteroendocrine cells [18] and recognizes natural and NNS. It has been reported that sucralose, as well as sucrose and glucose, induces the release of GLP1 in human enteroendocrine cells NCI-H716, nevertheless, at higher concentrations $(20 \mathrm{mM})$, GLP-1 release is inhibited and returns to basal levels [33], which implies that there is a not-yet described mechanism that quenches the signal. In the present study, none of the intervention groups received such a high dose $(48 \mathrm{mg}$ and $96 \mathrm{mg}$ of sucralose are equivalent to $2 \mathrm{mM}$ and 4 $\mathrm{mM}$, respectively); however, sucralose pharmacokinetics in the human body should be considered. Sucralose takes more than $72 \mathrm{~h}$ to be eliminated; in feces and urine sucralose can be detected more than 72-96 h after ingestion of a single dose, while in plasma sucralose is still 
detectable $72 \mathrm{~h}$ after ingestion [34]. Since we gave a daily dose of sucralose for 10 weeks to participants, sucralose may have been accumulated thus increasing the total amount to which participants were exposed, blunting the signals of sucralose on the receptors, especially in the $96 \mathrm{mg}$ sucralose group.

Besides, it should be mentioned that our study did not find a beneficial effect of sucralose consumption on BMI, HOMA, cholesterol or triglycerides, which agrees with other studies that reported limited or no effects of NNS consumption on reduction of caloric intake and consequently BMI or other clinical manifestations associated with obesity [35]. Even more, in adolescents the consumption of NNS has been associated with greater probability of obesity [36]. To our knowledge, this is the largest randomized, double blind, controlled trial challenging the glucose-insulin axis in healthy volunteers, with normal weight and HOMA values, who were exposed to NNS with two different sucralose amounts (48 and $96 \mathrm{mg}$ ) for 10 weeks.

\section{Limitations of the study}

A major limitation in our study was the limited effects in the $96 \mathrm{mg}$ sucralose group, since the exact mechanism of the observed effects is unknown. Differences in adherence to intervention between groups also limit data interpretation. Furthermore, the moment at which sucralose was ingested daily was not registered, therefore subjects may not have ingested the sucralose at the same hour daily, or may have combined it with different foods, which may have altered the response to intervention. Nonetheless, in a real scenario, people do not ingest sucralose alone diluted in simple water; sucralose is found in different foods and beverages which contain a complex mixture of ingredients and often, other NNS too. Also, diet was not controlled, however, there were no statistically significant differences in carbohydrate, lipids or proteins intake between groups after 10 weeks of sucralose or placebo ingestion, although micronutrients were not measure. Likewise, gut microbiota changes were not assessed.

Finally, the use of water as a placebo in the control group may not be the best election in all studies, especially those who wish to assess the cephalic response to sweetness. In our case, we did not avoid this response, however, if we had used another substance as a control, for example, another NNS or sugar, we would not have discerned the effect of sucralose from that of the substance used as control. Further studies with sucralose encapsulated should be still conducted.

\section{Conclusion}

This study adds new evidence regarding the effect of chronic sucralose consumption on serum insulin and insulin sensitivity.
An effect of chronic consumption of sucralose on insulin response in healthy volunteers subjected to an OGTT was observed, however, the effect was not consistent with dose.

Further research is required before mayor claims can be made regarding the effect of sucralose consumption on glucose and insulin responses.

\section{Abbreviations \\ ANOVA: Analysis of variance; AUC: Areas under the curve; BMl: Body mass index; GLP - 1: Glucagon-like peptide 1; Hb1Ac: Hemoglobin glycated; HDL: High density lipoproteins; HOMA: Hemoglobin model assessment; LDL: Low density lipoproteins; NNS: Non-nutritive sweeteners; NSAID: No steroidal anti-inflammatory drugs; OGTT: Oral glucose tolerance test; SD: Standard deviation; TAS1R2: Taste receptor type 1 member 2; TAS1R3: Taste receptor type 1 member 3; WHR: Waist-to-hip ratio}

\section{Acknowledgements}

We thank to Dr. Blair Brown, who revised the English version of the manuscript and the staff at the Laboratory for Proteomics and Metabolomics of the General Hospital of Mexico "Dr. Eduardo Liceaga" for all contributions.

\section{Authors' contributions}

$\mathrm{BHN}$ and EVM equally contributed to this work. The authors' responsibilities were as follows: MMG and BHN conceived and designed research; EG and EVM analyzed data; ASR, GAAY, DLBKL, EFAJ and MMVM were responsible for the coordination and routine function of the protocol, recruitment, recollection, and analysis of data; SMGA, RBA and LHM participated in the conduction of the research; MMG, BHN and EVM wrote the paper; MMG had primary responsibility for final content. All authors read and approved the final manuscript.

\section{Funding}

This study was funded by Consejo Nacional de Ciencia y Tecnología (CONACYT, FOSSIS fund No. 261575).

\section{Availability of data and materials}

We have made publicly and freely available without restriction the data described in the manuscript, at: https://www.dropbox.com/s/8waa4iev5 0eeoo9/Public\%20database.xlsx?dl=0

\section{Ethics approval and consent to participate}

The study was approved by the Ethics and Clinical Research committees of the General Hospital of Mexico Dr. Eduardo Liceaga, with the number: DI/16/ 301/03/022.

Consent for publication

All authors approved the publication of the manuscript in the Nutrition Journal.

\section{Competing interests}

The authors declare that they have no competing interests.

\section{Author details}

${ }^{1}$ Laboratory of Proteomics and Metabolomics, Research Division, General Hospital of Mexico "Dr. Eduardo Liceaga", Mexico City, Mexico. ${ }^{2}$ Clinical Nutrition Division, General Hospital of Mexico Dr. Eduardo Liceaga, Mexico City, Mexico. ${ }^{3}$ Division of Clinical Pharmacology Research Division, General Hospital of Mexico "Dr. Eduardo Liceaga", Mexico City, Mexico. ${ }^{4}$ Clinic of Medical and Nutritional Trials (MENTRIALS), Mexico City, Mexico.

Received: 26 September 2019 Accepted: 24 March 2020

Published online: 13 April 2020

\section{References}

1. World Obesity Federation. Global Obesity Observatory | Obesity prevalence worldwide - Adults. Available from: https://www.worldobesitydata.org/map/ overview-adults. [cited 2019 Apr 29]. 
2. Rippe JM, Angelopoulos TJ. Relationship between Added Sugars Consumption and Chronic Disease Risk Factors: Current Understanding Nutrients. 2016;8(11).

3. Shankar P, Ahuja S, Sriram K. Non-nutritive sweeteners: review and update. Nutrition. 2013;29:1293-9.

4. Sylvetsky AC, Rother Kl. Trends in the consumption of low-calorie sweeteners. Physiol Behav. 2016;164:446-50.

5. Erythropel HC, Kong G, deWinter TM, O'Malley SS, Jordt SE, Anastas PT, et al. Presence of High-Intensity Sweeteners in Popular Cigarillos of Varying Flavor Profiles. JAMA. 2018;320:1380.

6. WHO, FAO, COMISSION CAC. REPORT OF THE 50th SESSION OF THE CODEX COMMITTEE ON FOOD ADDITIVES. 2018. Available from: http://www.fao.org/ fao-who-codexalimentarius/sh-proxy/en/? Ink=1\&url=https\%253A\%252F\%252 Fworkspace.fao.org\%252Fsites\%252Fcodex\%252FMeetings\%252FCX-711-5 0\%252FReport\%252FREP18 FAe.pdf. [cited 2019 Apr 29].

7. Chattopadhyay S, Raychaudhuri U, Chakraborty R. Artificial sweeteners - a review. J Food Sci Technol Springer. 2014;51:611-21.

8. Food and Drug Administration. High-Intensity Sweeteners. Available from: https://www.fda.gov/food/food-additives-petitions/high-intensitysweeteners. [cited 2019 Aug 26].

9. Sylvetsky AC. Metabolic effects of low-calorie sweeteners: a brief review. Obesity. 2018;26:S25-31.

10. Pepino MY, Tiemann CD, Patterson BW, Wice BM, Klein S. Sucralose affects glycemic and hormonal responses to an oral glucose load. Diabetes Care. 2013;36:2530-5.

11. Suez J, Korem T, Zeevi D, Zilberman-schapira G, Thaiss CA, Maza O, et al. Artificial sweeteners induce glucose intolerance by altering the gut microbiota. Nature. 2014;514:181-6

12. Nettleton JE, Reimer RA, Shearer J. Reshaping the gut microbiota: Impact of low calorie sweeteners and the link to insulin resistance? Physiol Behav. 2016;164:488-93.

13. Daly K, Darby AC, Shirazi-Beechey SP. Low calorie sweeteners and gut microbiota. Physiol Behav. 2016;164:494-500

14. Goza R, Bunout D, Barrera G, de la Maza M, Hirsch S. Effect of acute consumption of artificially sweetened beverages on blood glucose and insulin in healthy subjects. J Nutr Food Sci. 2018;08:1-5.

15. Grotz VL, Pi-Sunyer X, Porte D, Roberts A, Richard TJ. A 12-week randomized clinical trial investigating the potential for sucralose to affect glucose homeostasis. Regul Toxicol Pharmacol. 2017;88:22-33.

16. Brown AW, Bohan Brown MM, Onken KL, Beitz DC. Short-term consumption of sucralose, a nonnutritive sweetener, is similar to water with regard to select markers of hunger signaling and short-term glucose homeostasis in women. Nutr Res. 2015;31:882-8.

17. Dhillon J, Lee JY, Mattes RD. The cephalic phase insulin response to nutritive and low-calorie sweeteners in solid and beverage form. Physiol Behav. 2017;181:100-9.

18. Greenfield JR, Chisholm DJ. How sweet it is: Intestinal sweet taste receptors in type 2 diabetes. Diabetes. 2013;62(10):3336-7.

19. Moher D, Hopewell S, Schulz KF, Montori V, Gøtzsche PC, Devereaux PJ, et al. CONSORT 2010 explanation and elaboration: updated guidelines for reporting parallel group randomised trials. J Clin Epidemiol Pergamon. 2010; 63:e1-37.

20. Qu HQ, Li Q, Rentfro AR, Fisher-Hoch SP, McCormick JB. The definition of insulin resistance using HOMA-IR for Americans of Mexican descent using machine learning. PLoS One. 2011:6:e21041.

21. Faul F, Erdfelder E, Lang A-G, Buchner A. G*Power 3: A flexible statistical power analysis program for the social, behavioral, and biomedical sciences. Behav Res Methods. 2007;39(2):175-91.

22. Bueno-Henández N, Alcántara-Suárez R, Pérez-Castañeda M, Hernández León YA, Ruíz-Barranco AL, Escobedo G, et al. Content Validity and Reliability of a Food Frequency Questionnaire with Intense Sweeteners (FFQIS) in a Hispanic Population. enviado a publicación. J Nutr Food Sci. 2018:8(4):716.

23. Matsuda M, DeFronzo RA. Insulin sensitivity indices obtained from oral glucose tolerance testing: comparison with the euglycemic insulin clamp. Diabetes Care. 1999:22:1462-70.

24. Grotz VL, Jokinen JD. Comment on Pepino et al. Sucralose affects glycemic and hormonal responses to an oral glucose load. Diabetes care. 2013:36: 2530-5 Diabetes Care. Medical Affairs, McNeil Nutritionals, Fort Washington, PA Igrotz@its.jnj.com. Office of Consumer Medical Safety, Johnson and
Johnson Consumer Products US, New Brunswick, NJ.: American Diabetes Association; 2014;37:e148.

25. Sylvetsky AC, Brown RJ, Blau JE, Walter M, Rother Kl. Hormonal responses to non-nutritive sweeteners in water and diet soda. Nutr Metab. 2016:13:71.

26. Lertrit A, Srimachai S, Saetung S, Chanprasertyothin S, Chailurkit L or,

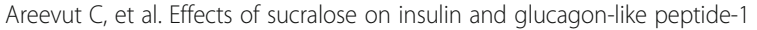
secretion in healthy subjects: A randomized, double-blind, placebocontrolled trial. Nutrition 2018;55-56:125-130.

27. Brown RJ, Rother KI. Non-nutritive sweeteners and their role in the gastrointestinal tract. J Clin Endocrinol Metab Narnia. 2012;97:2597-605.

28. Davis JN, Asigbee FM, Markowitz AK, Landry MJ, Vandyousefi S, Khazaee E, et al. Consumption of artificial sweetened beverages associated with adiposity and increasing HbA1c in Hispanic youth. Clin Obes. 2018:8:236.

29. Wang QP, Lin YQ, Zhang L, Wilson YA, Oyston LJ, Cotterell J, et al. Sucralose Promotes Food Intake through NPY and a Neuronal Fasting Response. Cell Metab. 2016;24:75-90.

30. Kojima I, Nakagawa Y, Hamano K, Medina J, Li L, Nagasawa M. GlucoseSensing Receptor T1R3: A New Signaling Receptor Activated by Glucose in Pancreatic $\beta$-Cells. Biol Pharm Bull. 2015;38:674-9.

31. Kojima I, Nakagawa Y, Ohtsu Y, Hamano K, Medina J, Nagasawa M. Return of the glucoreceptor: glucose activates the glucose-sensing receptor T1R3 and facilitates metabolism in pancreatic $\beta$-cells. J Diabetes Investig. 2015;6: 256-63.

32. Pepino MY. Metabolic effects of non-nutritive sweeteners. Physiol Behav. 2015;152:450-5.

33. Jang HJ, Kokrashvili Z, Theodorakis MJ, Carlson OD, Kim BJ, Zhou J, et al. Gut-expressed gustducin and taste receptors regulate secretion of glucagon-like peptide-1. Proc Natl Acad Sci U S A. 2007;104:15069-74.

34. Roberts A, Renwick AG, Sims J, Snodin DJ. Sucralose metabolism and pharmacokinetics in man. Food Chem Toxicol. 2000;38:31-41.

35. Wiebe N, Padwal R, Field C, Marks S, Jacobs R, Tonelli M. A systematic review on the effect of sweeteners on glycemic response and clinically relevant outcomes. BMC Med. 2011/11/19. Department of Medicine, 13-103 Clinical Sciences Building, University of Alberta, Edmonton, Alberta, T6G 2 G3 Canada.: BioMed Central; 2011:9:123.

36. Sylvetsky AC, Jin Y, Mathieu K, DiPietro L, Rother Kl, Talegawkar SA. Lowcalorie sweeteners: disturbing the energy balance equation in adolescents? Obesity. 2017;25:2049-54.

\section{Publisher's Note}

Springer Nature remains neutral with regard to jurisdictional claims in published maps and institutional affiliations.

\section{Ready to submit your research? Choose BMC and benefit from:}

- fast, convenient online submission

- thorough peer review by experienced researchers in your field

- rapid publication on acceptance

- support for research data, including large and complex data types

- gold Open Access which fosters wider collaboration and increased citations

- maximum visibility for your research: over $100 \mathrm{M}$ website views per year

At $\mathrm{BMC}$, research is always in progress.

Learn more biomedcentral.com/submissions 